\title{
PENDIDIKAN KARAKTER KEBANGSAAN DALAM SYIIR NGUDI SUSILO DAN SYIIR MITRA SEJATI KARYA KH. BISRI MUSTOFA REMBANG
}

\author{
Yamanto Isa \\ Universitas Baturaja \\ Jl. Ratu Penghulu No.2301, Baturaja, Sumatera Selatan, 32115 \\ E-mail: yamantoisagilzany@yahoo.com
}

\begin{tabular}{c|c|c}
\hline Received: & Revised: & Approved: \\
25/07/2018 & $01 / 08 / 2018$ & $20 / 09 / 2018$ \\
\hline
\end{tabular}

DOI: http://dx.doi.org/10.32332/akademika.v23i2.1164

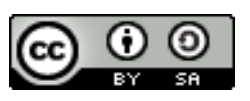

Pendidikan Karakter Kebangsaan dalam Syiir Ngudi Susilo dan Syiir Mitra Sejati Karya KH. Bisri Mustofa Rembang Licensed Under a Creative Commons Attribution-ShareAlike 4.0 International License

\begin{abstract}
The following generation of Indonesia should possess national characters for they will be the foundation for the continuity of the nation. One possible way to support such notion is through the character internalization. The transmission of the values of the character of a good citizen can be done through education. This article examines how KH. Bisri Musthofa instilled the spirit and values of the nation to the next generation through his two books, Syiir Ngudi Susila and Syiir Mitra Sejati. In the Syriir Ngudi Susila, KH. Bisri Mustofa urged that a child should have a strong foundation of personal character before carrying out a big mandate in the future. While in Syiir Mitra Sejati, KH. Bisri Musthofa taught important principles of becoming a good person for family, society, community, and nation.
\end{abstract}

Keywords: Character Education, Citizen, and Syiir Ngudi Susila 


\begin{abstract}
Abstrak
Generasi penerus bangsa wajib memiliki karakter kebangsaan yang akan menjadi tumpuan bagi kelangsungan bangsanya. Salah satu caranya adalah dengan melakukan internalisasi nilai-nilai karakter warga negara yang baik. Transmisi nilai-nilai karakter warga negara yang baik bisa dilakukan melalui pendidikan. Artikel ini mengkaji bagaimana KH. Bisri Musthofa menanamkan semangat dan nilai-nilai kebangsaan kepada generasi penerus melalui dua kitabnya, Syiir Ngudi Susila dan Syiir Mitra Sejati. Dalam kitab Syiir Ngudi Susila, KH. Bisri Mustofa mengajarkan agar seorang anak memiliki fondasi karakter pribadi yang kuat sebelum mengemban amanah yang besar di masa depan. Sedangkan dalam kitab Syiir Mitra Sejati, KH. Bisri Musthofa mengajarkan prinsip-prinsip penting dalam menjadi pribadi yang baik dalam lingkungan keluarga, sosial, masyarakat, hingga menjadi warga negara yang baik secara lebih detil dan mendalam.
\end{abstract}

Kata kunci: Pendidikan Karakter, Warganegara, dan Syiir Ngudi Susila

\title{
A. Pendahuluan
}

Bangsa adalah sebuah komunitas yang aneh. Ia mencakup sekumpulan komunitas manusia dalam jumlah yang luar biasa banyak. Hampir dipastikan mereka belum pernah saling bertemu apalagi saling mengenal. Meskipun demikian, uniknya mereka bisa saling merasa sebagai bagian dari satu bangsa yang sama. Lalu apa yang menyatukan mereka? Tentu saja ada banyak, diantaranya adalah: warna kulit, suku, ras, bahasa, tempat tinggal, hingga kesamaan nasib.

Fakta bahwa para anggota sebuah bangsa tidak pernah bertemu sebelumnya ini menyebabkan mereka hidup dalam sebuah bayangan atau khayalan akan kesamaan yang ada pada diri mereka. Benedict Anderson menyebut mereka sebagai komunitas khayalan atau imagined communities. ${ }^{1}$ Dalam konteks Indonesia, anggota bangsa ini terdiri atas ratusan suku; puluhan agama; ratusan kepercayaan; beberapa warna kulit; ratusan bahasa; tinggal terpisah di puluhan ribu pulau. Lalu apa yang menyatukan mereka?

Jawabnya adalah penjajahan. Seluruh bangsa Indonesia dari Sabang sampai Merauke, dari Miangas sampai Rote memiliki nasib yang sama, yakni sama-sama pernah dijajah oleh Belanda dalam rentang

${ }^{1}$ Benedict Anderson, Imagined communities: Reflections on the origin and spread of nationalism (Verso Books, 2006). 
waktu yang berbeda-beda hingga 350 tahun. Mereka juga pernah dijajah oleh Jepang selama sekira 3,5 tahun. ${ }^{2}$ Memori akan kelamnya nasib masa lampau menjadi pelecut bersama untuk melakukan perubahan menggapai kemerdekaan dan kesejahteraan di masa depan.

Memori dan bayangan inilah yang menjadi kekuatan sekaligus kelemahan bangsa Indonesia. Jika memori ini kuat, maka bangsa ini kuat. Jika memori ini melemah, maka ikatan bangsa Indonesia bisa mengendur. Sebab itulah NKRI sebagai pengejawantahan nation-state dari bangsa Indonesia selalu menyelenggarakan berbagai upaya memorial untuk menjaga memori tersebut, mulai dari membakukan pembelajaran sejarah di sekolah, membangun monumen, dan memorial park, menganugerahkan gelar pahlawan nasional. Demikian juga memperingati hari-hari bersejarah, hingga menetapkannya sebagai hari libur nasional.

Lalu bagaimana peran masyarakat sipil dalam merawat memori dan menyiapkan generasi bagi kemajuan bangsa di masa depan? Ada banyak peran yang bisa dilakukan. Misalnya dengan melakukan penanaman karakter dan transfer semangat kebangsaan dari satu generasi ke generasi lain. Salah satunya dilakukan oleh KH. Bisri Musthofa Rembang. Ia adalah tokoh empat zaman sejak zaman Belanda, Jepang, Orde Soekarno, hingga Orde Baru.

Dalam konteks sosial keagamaan, KH. Bisri Musthofa memiliki karakter moderat. Hal ini bisa dilihat dari sikapnya yang akomodatif terhadap perubahan zaman. Terhadap pemerintah yang bersifat represif, ia bersikap akomodatif tetapi tetap memegang prinsip dasar perjuangan Islam. Ia tidak menolak MPRS, demikian juga fusi partai Islam ke dalam PPP. Dalam hubungan sosial, KH. Bisri menggabungkan pemahamannya akan ushul fikih yang lentur, visioner, tapi sekaligus kontekstual. ${ }^{3}$

Dalam upaya mengisi kemerdekaan sekaligus menyiapkan generasi bangsa yang brilian dan mampu menjadi pemimpin bangsa, KH. Bisri Musthofa mengarang beberapa kitab untuk generasi penerus bangsa. $\mathrm{KH}$ Bisri memilih kitab sebagai media transfer semangat kebangsaan karena

${ }^{2}$ Merle Calvin Ricklefs, Sejarah Indonesia Modern, 1200-2004 (Jakarta: Penerbit Serambi, 2005).

${ }^{3}$ Munawir Aziz, "Produksi Wacana Syiar Islam dalam Kitab Pegon Kiai Saleh Darat Semarang dan Kiai Bisri Musthofa Rembang," Jurnal Afkaruna 9, no. 2 (Desember 2013): 121. 
media ini lebih awet, bisa direplikasi, dan didistribusikan kepada audiens yang sangat luas dengan cepat, tepat, dan relatif murah. Ada banyak kitab yang telah ia tulis. Dua di antaranya yang menarik adalah Syiir Ngudi Susila dan Syiir Mitra Sejati. Dua kitab ini ditulis khusus untuk dikonsumsi guru-guru mengaji untuk dibacakan dan diajarkan kepada santri-santri madrasah dan pesantren sebagai penerus generasi bangsa.

Bagaimana KH. Bisri Musthofa melakukan peran penting dalam dua kitab tersebut? Artikel ini berupaya menjawabnya dengan pembacaan filologis. Hal ini karena kedua kitab tersebut adalah teks klasik yang bisa didekati dengan pendekatan tekstual sekaligus kontekstual.

\section{B. Biografi Intelektual KH. Bisri Musthofa}

KH. Bisri Musthofa terlahir dengan nama kecil Masyhadi di Gang Palen, Pesawahan, Rembang, Jawa Tengah pada 31 Desember 1915. Ayahnya adalah seorang kiai kampung bernama KH. Zainal Musthofa. Sedangkan ibunya bernama Hj. Khatijah. Pendidikan dasarnya diselesaikan di Sekolah Angka Loro atau sekolah untuk bumiputera di Jawa. Setamat sekolah ini Masyhadi melanjutkan studi di Pesantren Kajen. Kemudian ia melanjutkan lagi ke Pesantren Kasingan di bawah asuhan KH. Cholil. Saat bulan puasa, ia mengaji di Pesantren Tebuireng, asuhan KH. Hasyim Asy'ari. ${ }^{4}$

Saat berusia dua puluh tahun Masyhadi diambil menantu oleh kiainya. Masyhadi dinikahkan dengan putri sang kiai yang bernama Ma'rufah. Menikah tak menghalangi semangatnya untuk melanjutkan studi. Ia malah segera berangkat ke Makkah untuk menunaikan ibadah haji sekaligus tinggal di sana untuk berguru kepada para ulama Makkah. Di antara beberapa gurunya adalah: Syeikh Baqil, asal Yogyakarta; Syeikh Umar Hamdan Al Maghriby, Syeikh Ali Malik, Sayid Amid, Syeikh Hasan Massath, Sayid Alwi dan KH. Abdullah Muhaimin. Perjalanan hajinya ia tuliskan dalam buku Tuntunan Ringkas Manasik Haji. ${ }^{5}$

${ }^{4}$ Aziz, 119.

${ }^{5}$ Faiz Karim Fatkhullah, "Pengalaman Spiritual K.H. Bisri Mustofa dalam Naskah Manasik Haji: Tinjauan Sosiologi Sastra (the Spiritual Experience of Kh Bisri Mustofa in Manasik Haji Manuscript: a Literary Socio- Logical Review)," Metasastra 6, no. 2 (2013): $65-82$. 
Setelah tuntas belajar di Mekah, ia dipanggil mertuanya untuk kembali ke Rembang. Ia pun segera kembali ke Rembang. Masyhadi kemudian mengganti nama menjadi Bisri dan menambahkan nama orangtuanya sehingga namanya menjadi Bisri Musthofa. Ia kemudian mengabdi di pesantren milik mertuanya. Pesantren Kasingan ini sempat vakum selama masa pendudukan Jepang. Bisri kemudian meneruskan pengajaran santri di Pesantren Raudlatut Thalibin, Leteh, Rembang. ${ }^{6}$

Di mata masyarakat KH. Bisri Syamsuri dikenal sebagai ulama dan aktivis serba bisa. Ia kiai yang mengasuh pesantren dengan ribuan santri. Ia aktivis dan pengurus Nahdlatul Ulama yang sangat berpengaruh. Ia adalah politisi yang pernah menjadi anggota Konstituante, anggota MPRS, dan anggota MPR. Ia penulis prolifik dengan 57 buku yang sudah diterbitkan. Ia ulama yang karyanya merentang dalam kajian ilmu al-Quran, tafsir, hadits, akidah, akhlak, tasawuf, ilmu mantik, sejarah, kumpulan doa, kumpulan khutbah, kumpulan dongeng, hingga naskah sandiwara. ${ }^{7}$

Karya-karya KH. Bisri Musthofa diterbitkan oleh penerbit Menara Kudus, Pustaka Progresif Surabaya, Toha Putra Semarang, dan Bahagia Pekalongan. Penerbit yang paling banyak menerbitkan adalah Menara Kudus. Karyanya yang paling monumental adalah Tafsir Al-Ibriz, sebuah tafsir al-Quran berbahasa Jawa setebal tiga jilid. Beberapa di antaranya diterbitkan dalam edisi per juz, sehingga ada 30 jilid. ${ }^{8}$

Mayoritas karya tersebut ditulis dalam bahasa Jawa menggunakan aksara Arab Pegon. Adapun sebagian di antaranya ditulis dalam bahasa Indonesia. Mayoritas karya berpola prosa. Beberapa di antaranya menggunakan pola syiir. Karya-karya ini ditujukan kepada pembaca awam, santri, hingga kiai. Karya-karyanya sangat populer karena dijadikan buku ajar dan bahan kajian di pesantren, madrasah, masjid, dan surau di seputaran Jawa, Sumatera, hingga Kalimantan.

Selain itu, KH. Bisri Mustofa juga menulis beberapa kitab dalam rumpun keilmuan akhlak. Dalam konteks ini, akhlak berbeda pengertian dengan etika yang merupakan cabang dari filsafat. Akhlak dipahami

${ }^{6}$ Aziz, "Produksi Wacana Syiar Islam dalam Kitab Pegon Kiai Saleh Darat Semarang dan Kiai Bisri Musthofa Rembang," 119-20.

7 Aziz, 120.

${ }^{8}$ Abu Rohkmad, "Telaah Karakteristik Tafsir Arab-Pegon Al-Ibriz," Analisa Journal of Social Science and Religion 18, no. 1 (3 Juni 2011): 27-38. 
sebagai seperangkat aturan bagaimana seseorang berperilaku, berbudi pekerti, dan memiliki perangai yang baik. Di pesantren dan madrasah, akhlak selain diposisikan sebagai mata pelajaran, juga dijadikan sebagai ilmu laku atau ilmu praktis. Ia diaplikasikan dalam keseharian. ${ }^{9}$

Setidaknya ada empat karya yang telah KH. Bisri Mustofa terbitkan dalam perkara akhlak ini, yakni Washaya al-Abaa' lil Abna (Wasiat Ayah kepada Anak), Syi'ir Ngudi Susila, Syiir Mitra Sejati, dan Qashidah alTa'liqatul Mufidah (Syarah Qashidah al-Munfarijah karya Syeikh Yusuf al Tauziri dari Tunisia). Tiga kitab terawal adalah kitab yang paling populer dan banyak dikaji oleh masyarakat. Dalam artikel ini, ada dua karya yang akan dikaji, yakni Syi'ir Ngudi Susila dan Syiir Mitra Sejati.

Kedua kitab ini mengunakan pola yakni syiir. Syiir di sini memiliki pengertian yang berbeda dengan syair yang lazim digunakan dalam tradisi kesusastraan Indonesia. Syiir di sini sebetulnya lebih dekat dengan bentuk nadzam dalam sastra Arab. Biasanya syiir ini ditulis dalam beberapa baris yang setiap barisnya memiliki dua penggal, depan dan belakang yang biasanya memiliki bunyi suku kata akhir yang sama. Masing-masing baris ini diikat oleh jumlah ketukan yang sama. Dalam tradisi keilmuan sastra Arab, syiir ini dikaji dalam ilmu 'arudh. Satu-satunya perbedaan syiir dengan nadzam adalah bahwa syiir dalam konteks ini menggunakan bahasa Jawa sedangkan nadzam menggunakan bahasa Arab.

Penggunaan syiir sebagai media karena memiliki beberapa kelebihan. Pertama, ia terikat dengan rima dan irama sehingga bisa dinyanyikan. Anak-anak tentu akan lebih tertarik dengan nyanyian ketimbang dengan teks biasa. Kedua, adanya momentum dan ketukan nada menyebabkan syiir mudah diterima, disenandungkan, dan dihafalkan sehingga bisa diinternalisasikan dalam sanubari anak-anak. Hal semacam ini lazim dalam pengajaran di pesantren. ${ }^{10}$

Syiir yang merupakan bagian dari salah satu wujud sastra menjadi media yang tepat untuk memuat pesan-pesan tertentu, termasuk pesan akhlak, karakter kebangsaan, dan nasionalisme. ${ }^{11}$ Jika dalam sastra yang

9 Samidi Khalim, "Akhlak Santri antara Teks dan Konteks," Analisa Journal of Social Science and Religion 16, no. 1 (2009): 37.

${ }^{10}$ Khalim, 40.

${ }^{11}$ Lustantini Septiningsih, "Tema Nasionalisme Dalam Pembelajaran Sastra: Upaya Menumbuhkan Semangat Kebangsaan*," Kajian Sastra 34, no. 2 (2010): 139-40. 
$100 \%$ fiksi saja, pesan-pesan moral dapat diemban, apalagi syiir ini bukan fiksi. Tentu saja pesan-pesan KH. Bisri akan lebih mudah diterima dan diinternalisasikan.

\section{Pendidikan Karakter Kebangsaan}

Karakter, sebagaimana ditulis Zubaedi, berasal dari bahasa Latin, karasso. Kata ini bermakna dasar atau cetak biru. Dalam khazanah kajian keislaman, karakter ini identik dengan akhlak. Sedangkan akhlak sendiri memiliki makna budi pekerti, perangai, atau perilaku. Al-Ghazali dalam Hasim menyatakan bahwa akhlak adalah suatu perangai atau watak yang menetap dalam jiwa seseorang yang merupakan sumber timbulnya perbuatan-perbuatan tertentu dari dirinya secara mudah dan ringan tanpa dipikirkan atau direncanakan sebelumnya.

Sementara itu, bangsa adalah sekumpulan masyarakat yang dibayangkan memiliki kesamaan. Antar anggotanya yang berjumlah ratusan juta ini tidak pernah saling bertemu apalagi saling mengenal tetapi memiliki merasa memiliki kesamaan. Salah satunya adalah kesamaan cita-cita untuk memperjuangkan nasib bersama. Sebagai bagian dan anggota dari sebuah bangsa, setiap anggotanya merasa menjadi bagian dan merasa perlu untuk berperan serta memajukan kepentingan dan nasib bangsanya.

Dari dua titik inilah, karakter kebangsaan dalam artikel ini didefinisikan sebagai karakter yang dilandasi oleh kesadaran kebangsaan yang kuat. Karakter ini akan membuat seseorang rela melakukan apa saja demi tercapainya cita-cita bersama sebagai sebuah bangsa yang kokoh lagi kuat. Karakter ini juga menuntun seseorang untuk rela melepaskan kenikmatan dan hak-hak pribadinya demi kepentingan dan kenikmatan yang dinikmati oleh komunitas yang lebih luas, yakni kepentingan dan kenikmatan bangsanya.

Pendidikan karakter kebangsaan di Nusantara sudah menjadi bagian inhern dalam pondok pesantren. Dalam catatan Naim, pesantren adalah lembaga pendidikan Islam pertama (sejak abad ke-13) yang sudah fokus dalam membentuk nilai, moral, dan watak sosial-budaya Indonesia. Pesantrenlah yang turut berperan besar dalam membentuk corak karakter bangsa Indonesia sejak abad ke-13 hingga abad ke-21 ini. 
Salah satu tokoh penting dari pesantren, misalnya, KH. Abdul Wahid Hasyim, putra pendiri Nahdlatul Ulama menegaskan bahwa ada delapan nilai karakter yang harus diajarkan kepada generasi penerus bangsa. Kedelapan karakter tersebut adalah: religius, toleransi, madiri, demokratis,semangat kebangsaan, cinta tanah air, bersahabat atau komunikatif, dan gemar membaca.

Pesantren lazimnya menyelenggarakan pendidikan karakter dalam dua metode. Pertama, pengenalan melalui pembelajaran yang biasanya menggunakan kitab kuning. Ratusan judul kitab tentang akhlak diajarkan di ribuan pesantren di Indonesia. Kedua, praktik langsung atau internalisasi bagaimana bertata krama. Pesantren memberikan jadwal kegiatan harian dan melakukan pengawasan terhadap hal ini untuk menginternalisasikan akhlak.

Akhlak yang diajarkan berbasis pada kajian Islam, terutama tasawuf. Tasawuf sendiri bisa dipahami sebagai sebuah ilmu, disiplin, upaya, seni, atau laku untuk menjernihkan hati, menyingkirkan segala kotoran dan penyakit hati. Ketika hati jernih, maka ia akan mencerminkan kejernihan sikap dan akhlak yang tak lain merupakan tindakan spontan.

\section{Identifikasi Kitab Syiir Ngudi Susila}

Syiir ini ditulis oleh KH. Bisri Musthofa dengan judul lengkap Syiir Ngudi Susila Saka Pitedah Kanthi Terwela. Kitab ini diterbitkan oleh Menara Kudus tanpa tahun terbit dan nomor cetakan. Kitab ini dicetak dalam ukuran saku dengan ketebalan 16 halaman ditambah sampul. Dalam catatan akhir, kitab ini selesai ditulis pada Jumadil Akhir $1373 \mathrm{H}$ atau sekitar Februari 1954 di Rembang.

Kitab ini terdiri dari beberapa bab, yakni: bab ambagi wektu, ing pamulangan, ono ing omah, karo guru, ono tamu, sikep lan lagak, dan cita-cita luhur. Diterjemahkan ke dalam bahasa Indonesia: bab membagi waktu, di sekolah, di rumah, sikap kepada guru, ketika ada tamu, sikap dan tindakan, dan cita-cita luhur. Kitab ini secara khusus ditujukan kepada anak-anak usia Sekolah Dasar.

Kitab ini lazim diajarkan kepada santri Madrasah Diniyah kelas 1 Awwaliyah atau di surau, pesantren, atau masjid. Metode pembelajaran 
yang biasanya dipakai adalah bandongan. Guru akan menuliskan beberapa bait syiir di papan tulis. Santri akan menyalinnya di buku masing-masing. Setelah selesai, guru membacakan syiir tersebut dengan lagu tertentu diikuti oleh santri secara bersama-sama. Selanjutnya, santri akan diminta menghafalkan.

Kitab ini tidak memiliki kata pengantar baik dari penulis atau dari tokoh lain yang ditulis dalam bentuk prosa. Kitab ini diawali dengan satu nadzam salawat, yakni: shalatullaahi maa lahat kawaakib ala ahmad khairi man rakiba an-najaaib. KH. Bisri kemudian menegaskan bahwa syiir ini ditujukan kepada anak, baik lelaki ataupun perempuan. Tujuannya adalah untuk menjauhkan anak-anak dari perilaku yang tercela.

Hal ini tampak pada tiga syair pertama Syiir Ngudi Susila.

Iki syiir kanggo bocah lanang wadon, nebihake tingkah laku ingkang awon Sarto nerangake budi kang prayuga, kangge dalan podo mlebu ing suwarga. Bocah iku wiwit umur pitung tahun, kudu belajar toto keben ora getun.

Ini syiir untuk anak lelaki dan perempuan, menjauhkan perilaku yang tercela. Juga menerangkan pekerti yang baik, agar mendapatkan jalan menuju surga. Ketika anak menginjak usia tujuh tahun, harus belajar tata krama agar tak menyesal nanti.

\section{E. Identifikasi Kitab Syiir Mitra Sejati}

Syiir ini ditulis oleh KH. Bisri Musthofa dengan judul lengkap Syiir Mitra Sejati Nerangake Ing Bab Budi Pekerti. Kitab ini diterbitkan oleh Penerbit Muhammad bin Ahmad Nabhan wa Awladuh Surabaya. Tidak ada tanggal penerbit dan nomor cetakan. Berbeda dengan Syiir Ngudi Susila yang mencatumkan tanggal selesai penulisan, Syiir Mitra Sejati tidak memilikinya, sehingga pembaca tidak bisa mengetahui kapan syiir ini selesai digubah.

Kitab ini terdiri atas 109 (seratus sembilan) baris syiir yang dibagi ke dalam 19 (sembilan belas) bab. Menariknya, kitab ini selesai digubah 
hanya dalam waktu satu malam. Kitab ini diawali dengan syair terkenal gubahan pujangga Abu Nawas berikut ini:

Ilaahi lastu lil firdausi ahla. Wa la aqwa 'alaa nar il-jahiimi.

Fahab lii tawbatan waghfir dzunubi. Fainnaka ghafiru adz-dzunubi.

Adapun pembagian bab dalam kitab ini adalah sebagai berikut: bab kamanungsan, sikepi anak marang Bapak, sikepe Bapak marang Ibu, sikepe rakyat maring pemerintah, sikepe murid maring guru, sikepe kita maring kanca, wenane tatakrama, bab ngrungokake gunemane wong, tatakramane guneman, carane sesrawungan kang bagus, ngrekso awak, tatakramane mangan, bab sandangan, bab omah lan kamar, kewajibane wong adiwoso, bab gemi, bab ziyarah lan tatakrama, bab tilik wong lara, bab takziyah wong kepaten, walimahan, kemajuan, lan kewajibane wong tuwo.

Jika diterjemahkan ke dalam bahasa Indonesia, bab-bab tersebut adalah: bab kemanusiaan, sikap anak kepada Bapak, sikap anak kepada Ibu, sikap rakyat kepada pemerintah, sikap murid kepada guru, sikap kita kepada sesama teman, tata krama, bab memperhatikan pembicaraan orang lain, etika berbicara, cara bergaul dengan baik, menjaga diri, tata krama makan, bab pakaian, bab rumah dan kamar, kewajiban orang dewasa, bab perhatian, bab etika berkunjung, bab menengok orang yang sakit, bab takziyah kepada orang yang sudah wafat, walimah, kemajuan, dan bab kewajiban orang tua.

Audiens yang dituju oleh kitab Syiir Mitra Sejati adalah siswa atau santri yang sudah mulai beranjak dewasa. Biasanya kitab ini diajarkan kepada santri tingkatan akhir di level Madrasah Diniyah Awwaliyah atau seusia SMP. Sesuai judul kitabnya, Mitra Sejati, pengarang memosisikan audiens sebagai mitra yang sudah cukup dewasa dan setara, bukan sebagai anak yang mesti diajari sesuatu dengan ikatan hierarkhis.

Cakupan pembahasan dalam Syiir Mitra Sejati cukup luas, ditandai dengan banyaknya bab yang mencapai 19. Selain itu, kajian juga lebih mendalam, hal ini ditandai dengan bab pembuka yang sangat reflektif. Yakni bab kamanungsan (kemanusiaan). Dalam bab ini pengarang mengajak pembaca untuk merenungkan posisi sebagai manusia biasa yang membutuhkan orang lain. Untuk bisa makan nasi, kita membutuhkan orang lain yang menanak nasi, yang menggiling gabah, pemetik gabah, dan petani yang menanam dan merawat padi. 
Saben wong urip mesti butuh liyan.

Sebab lamun ijen temtu ora mangan.

Bade dahar butuh wong kang adang sekul

Wong kang nutu, lan kang nandur, lan kang macul.

Setiap kita selalu membutuhkan orang lain,

Sebab jika kita sendirian, tentu tak akan bisa makan.

Hendak makan kita butuh orang yang menanak nasi, yang menggiling gabah, yang menanam padi, dan yang mengolah lahan.

\section{F. Pendidikan Karakter Kebangsaan dalam Syiir Ngudi Susila}

Secara prinsipil, Syiir Ngudi Susila meletakkan fondasi penting bagi pembangunan akhlak anak. Dalam catatan Hasim, terdapat dua karakter yang hendak dibangun dalam Syiir Ngudi Susila ini, yakni rasa hormat dan tanggung jawab. Rasa hormat dalam Syiir Ngudi Susila ini diupayakan lahir dari kesadaran akan posisi seseorang dalam lingkungan sekitar, baik lingkungan kebendaan maupun lingkungan sosial.

Dalam lingkungan yang lebih luas, rasa hormat ini dikembangkan dalam lingkungan sosial di keluarga bersama orangtua dan kerabat; di sekolah bersama dewan guru dan teman belajar; di perjalanan bersama teman seperjalanan; dan bersama orang asing misalnya tamu. Sikap hormat ini sangat ditekankan oleh KH. Bisri Musthofa. Ia tidak ingin sikap hormat ini mewujud sebagai pengetahuan semata, melainkan merembes ke dalam perilaku sehari-hari.

Terhadap orangtua, KH Bisri Musthofa menekankan pentingnya peran mereka dalam kehidupan. Mereka berdualah yang menjadi sebab kejadian dan merawat semenjak bayi. Dalam syiirnya disebutkan,

Kudu tresno ring ibune kang ngrumati, kawit cilik marang bapak kang gemati.

Ibu bapak rewangono lamun repot, ojo koyo wong gemagus ingkang wangkot. Lamun ibu bapak printah inggal tandang, ojo bantah ojo sengol ojo mampang.

Harus cinta kepada ibu yang setia merawat, sejak kecil, juga cinta Ayah yang teramat telaten. 
Bantulah Ibu Bapak ketika sedang kerepotan, jangan sok tampan nan sombong. Jika Ibu Bapak memerintah, segera tunaikan. jangan membantah, jangan sewot, dan jangan menantang.

Demikian halnya sikap terhadap guru. KH. Bisri menekankan pentingnya hormat kepada guru; memperhatikan penjelasan, nasihat, dan larangan. Sama halnya sikap terhadap teman sepermainan. KH. Bisri berpesan agar bersikap secara baik, memperlakukan mereka dengan baik, rukun, dan bisa memosisikan diri dalam struktur sosial keluarga.

Dalam dalam sektor yang lebih luas, KH. Bisri memperhatikan agar para santri selain mengejar ilmu pengetahuan, juga memiliki akhlak yang terpuji. Karena banyak orang yang cerdas secara intelektual tetapi minus dalam perkara akhlak. Mengejar kemajuan dan modernitas juga merupakan hak, tetapi identitas diri jangan sampai hilang sehingga malu dengan identitas kebangsaan.

KH. Bisri mengkritik anak muda yang menertawakan pakaian tradisional sarung, surban, dan blangkon yang dianggapnya tidak modern. KH Bisri menyatakan,

Sawang iku Pangeran Diponegoro
Imam Bonjol, Teuku Umar kang kuncara.
Kabeh podo mbelo bongso lan negoro,
Podo ngagem destar pantes yen perwira
Gujeng serban sasat gujeng Imam Bonjol,
Sak kancane hei anakku ojo tolol.

Lihatlah Pangeran Diponegoro,

Imam Bonjol, Teuku Umar yang terkenal.

Semua membela bangsa dan negara,

Mereka mengenakan destar yang pantas dan gagah.

Menertawakan serban sama halnya menertawakan Imam Bonjol

Dan teman=teman seperjuangannya, Anakku, jangan begitu.

KH. Bisri mencontohkan tiga tokoh pahlawan nasional, yakni Pangeran Diponegoro, Imam Bonjol, dan Teuku Umar. Ketiganya adalah pejuang penting di republik ini. Ketiganya digambarkan sebagai pahlawan patriot yang memperjuangkan kemerdekaan bangsanya. Ada yang 
menarik di sini. Jika kebanyakan ulama mengutip para sahabat Nabi untuk menggambarkan heroisme, KH. Bisri justru menggambarkan heroisme dengan menampilkan pejuang dan pahlawan lokal.

Pilihan ini menarik karena dengan demikian, KH. Bisri mempopulerkan pahlawan nasional dalam spektrum santri dengan karakternya yang khusus. KH. Bisri mengingatkan peran penting para pahlawan dalam memperjuangkan bangsanya. KH. Bisri juga mengkampanyekan sikap kepahlawanan yang identik dengan harga diri kebangsaan yang kuat di hadapan bangsa asing.

Syiir Ngudi Susila juga memperhatikan cita-cita yang perlu dipacak sepenting mungkin,

Anak Islam kudu cita-cita luhur, keben donya akhirate bisa makmur. Cukup ilmu umum lan agamane, cukup donya kanti bekti pengerane. Bisa mimpin sedulure lan bangsane, Tumuju ring kaharja lan kemulyane. Kita iki bakal tininggal wong tuwa ora kena ora kita mesti muwa.

Anak Islam harus memiliki cita-cita luhur, agar dunia dan akhirat menjadi makmur. Menguasai ilmu umum dan ilmu agama, menguasai dunia serta berbhakti kepada Tuhan.

Bisa menjadi pemimpin bagi saudara dan bangsa, menuju kejayaan dan kemuliaan

Kelak kita akan ditinggal wafat orang tua mau tak mau kita akan menjadi dewasa.

KH. Bisri menegaskan bahwa generasi muda harus memiliki citacita yang tidak hanya tinggi, tetapi luhur. Cita-cita tinggi hanya berupaya memenuhi hasrat pribadi. Sedangkan cita-cita luhur adalah cita-cita yang memenuhi hasrat dan kebutuhan diri dan bangsanya. Keluhuran cita-cita ini mencakup kemakmuran di dua alam: alam dunia dan alam akhirat.

Mencapai cita-cita ini tidak mudah. Sebab itu KH. Bisri mengajarkan lima syarat yang harus dipenuhi. Pertama dan kedua, memiliki ilmu umum dan ilmu agama. Ilmu umum adalah ilmu yang secara lahiriah 
bersifat profan, tidak terkait dengan agama. Sedangkan ilmu agama adalah ilmu yang mengantarkan pada pengetahuan akan ketuhanan. Dualisme keilmuan ini sepertinya menjadi kelaziman di kalangan pesantren, meskipun sesunggunya tiada dualisme. Yang ada adalah pemilahan bidang keilmuan.

Syarat ketiga adalah menguasai dunia atau memiliki basis perekonomian yang kokoh. Generasi muda harus mampu memenuhi hajat hidupnya dan keluarganya dengan jalan yang halal dan baik. Keempat, tiga hal yang tadi digunakan untuk berbakti kepada Allah. Penguasaan ilmu bukan untuk ilmu itu sendiri. Penguasaan ekonomi bukan untuk memenuhi hasrat ekonomi belaka. Namun kesemuanya bermuara pada ketaatan kepada yang maha kuasa.

Syarat kelima adalah memiliki jiwa dan skill kepemimpinan yang kokoh untuk memimpin saudara dan bangsanya. KH. Bisri mendahulukan saudara. Ini artinya bahwa menjadi pemimpin adalah sebuah proses pembelajaran jangka panjang. Pemimpin dilahirkan melalui proses, tidak taken for granted. Ia harus mengolah segala kemampuan, dari proses yang sederhana, memimpin diri sendiri, memimpin keluarga, memimpin saudara, hingga akhirnya menjadi pemimpin bagi bangsanya.

$\mathrm{KH}$. Bisri menggarisbawahi perlunya regenerasi kepemimpinan bangsa. Bahwa kelak orangtua akan pergi meninggalkan kita. Kelak kita juga akan menjadi tua, tetapi belum tentu menjadi dewasa. Sebab itu, mau tak mau kita harus memproses diri, menyiapkan diri untuk menjadi lebih dewasa. Dalam konteks yang lebih luas, KH. Bisri menyebutkan beberapa peran yang bisa diambil oleh generasi muda.

Negaramu butuh menteri butuh mufti, butuh qadhi, patih, seten, lan bupati.

Butuh dokter, butuh mister ingkang pinter, Ilmu agama kang nuntun laku bener.

Butuh guru lan kiai kang linangkung,

Melu ngatur negarane ora ketung.

Negaramu membutuhkan menteri dan mufti, membutuhkan hakim, perdana menteri, pejabat, bupati, membutuhkan dokter, ahli hukum yang cerdas. membutuhkan ahli agama yang menuntun perilaku yang benar Membutuhkan guru dan kiai yang mumpuni, turut mengelola kepentingan negara. 
KH. Bisri Mustofa tidak membedakan penguasaan ilmu agama ataupun ilmu umum. Semua harus dikuasai sesuai dengan bakat dan minat masing-masing. KH. Bisri menyebutkan beberapa bidang yang harus diisi, misalnya politik eksekutif (menteri, patih, bupati); yudikatif (qadhi); kaum profesional (dokter, mister); akademisi (guru); ahli agama (kiai, mufti). Semua berperan dalam menjalankan roda negara dan pemerintahan agar semua kebutuhan rakyat terpenuhi, agar kesejahteraan rakyat tercapai.

\section{G. Pendidikan Karakter Kebangsaan dalam Syiir Mitra Sejati}

Karakter kebangsaan dalam Syiir Mitra Sejati dimulai dari pengenalan akan hak dan kewajiban seorang kepada diri sendiri dan orangtua. Ini adalah bekal dasar seorang warganegara yang baik. KH. Bisri Musthofa dalam Syiir Mitra Sejati menekankan bahwa orangtua sudah berkorban banyak untuk kepentingan anaknya.

Kawit cilik bapak ira mikiraken, nasib ira abot payah gak direken.

Mangan ngombe nyandang kabeh butuh ira,

Dicukupi bapak, uga ngaji ira.

Payah opo kang den songgo dening ibu, ngandut sangang wulan nuli dadi babu.

Mula sira aja lali males budi, aja wani mundak wani marang nyang widhi. ${ }^{12}$

Sejak kecil bapakmu sudah memperhatikan, Nasibmu, payah kerepotan tak pernah dihiraukan

Makanan, minuman, pakaian, semua kebutuhanmu dicukupi Bapak, demikian halnya pendidikanmu. Betapa payah ibumu menyandang bayimu, mengandung sembilan bulan, lalu menjadi pembantumu. Maka jangan pernah lupa untuk membalas budi, jangan durhaka kepada orangtua, nanti durhaka kepada Yang Maha Esa.

Ayah dan Ibu sudah bekerja keras, bekerja ekstra untuk memenuhi segala kebutuhan anaknya. Ayah sudah mengorbankan hari-harinya, mencari nafkah untuk memenuhi segala keperluan, mulai dari makan, minum, pakaian, hingga pendidikan. Sang Ibu menghabiskan waktunya

12 Bisri Musthofa, Syiir Mitra Sejati Nerangake Ing Bab Budi Pekerti (Surabaya: Muhammad bin Ahmad Nabhan, n.d.), 2-3. 
untuk mengandung dan merawat anak sejak bayi. KH. Bisri menekankan agar kita berupaya membalas budi yang baik kepada keduanya. Betapa berat dosa durhaka kepada orangtua sehingga KH. Bisri Musthofa menyetarakan durhaka kepada orangtua dengan durhaka kepada Yang Maha Esa.

Terhadap pemerintah, KH. Bisri Musthofa mengajarkan kepada kita untuk menjadi warga negara yang baik. Fungsi dan peran sebagai warga negara ini diulas panjang lebar dalam lima baris syiir Mitra Sejati. Hal ini karena kajian Syiir Mitra Sejati memang ditujukan kepada pribadi yang telah cukup umur untuk diajak berdiskusi tentang hal-hal ini. KH. Bisri menjelaskan fungsi dan peran pemerintah yang baik dalam syiir berikut:

Kita ngerti yen pemerintah kita iku ngatur samubarang tindak laku Wongkang zolim kampak begal diadili, kabeh kepentingan umum diperduli Kesehatan kemakmuran keamanan pendidikan pengajaran kretek dalan Kabeh mahu diopeni lan ditata kanggo kepentingan kita podo rata Mula kita kudu tunduk ora mampang lan bantu keben ora dha gemampang. ${ }^{13}$

Kita tahu bahwa pemerintah mengatur segala hal, juga segala kepentingan.

Orang zalim, begal kapak diadili.

Semua kepentingan umum diperhatikan.

Kesehatan, kemakmuran, keamanan, pendidikan, pengajaran, jembatan, dan jalan.

Semua itu dirawat dan ditata, untuk kepentingan bersama tanpa kecuali. Maka kita wajib tunduk, tidak membangkang, membantu agar semua menjadi lancar.

KH. Bisri menjelaskan bahwa secara prinsipil, pemerintah yang baik adalah pemerintah yang memperhatikan dan memenuhi hajat hidup masyarakat. Fungsi yang paling fundamental disebut lebih awal, yakni menegakkan keadilan. Hak diberikan kepada yang berhak. Sanksi dijatuhkan kepada pihak yang melanggar hukum. Semua kepentingan publik dipenuhi, mulai dari kesehatan, kemakmuran, keamanan,

${ }^{13}$ Musthofa, 3. 
pendidikan, hingga infrastruktur. Semua hal diperhatikan demi kepentingan bersama, bukan kepentingan golongan tertentu.

Oleh sebab itu, sebagai warga negara yang baik, generasi muda harus tunduk dan taat kepada pemerintah, tidak membangkang apalagi sampai memberontak. Warga negara yang baik berkewajiban untuk membantu terlaksananya pemenuhan kepentingan publik oleh pemerintah di atas. Hal ini hanya mungkin bisa dilakukan jika dilandasi oleh rasa cinta yang mendalam terhadap negaranya.

Tata krama itu akeh tuladhane

kaya temen aris demen negarane ${ }^{14}$

Tata krama itu banyak teladannya semisal air muka ceria penuh semangat dan cinta negara.

KH. Bisri Musthofa menjadikan cinta tanah air sebagai salah satu wujud keteladanan dalam akhlak atau tata krama. Cinta negara atau tanah air ia sepadankan dengan air muka yang senantiasa ceria dan penuh semangat. Tentu saja cinta yang menyala akan membawa air muka yang ceria, alih-alih bersedih.

Syiir Mitra Sejati juga menerakan kewajiban pribadi yang sudah dewasa. Ia menyebutkan,

Yen wus adiwasa kudu nyambut gawe

golek rizki halal aja klawe-klawe

Opo maneh wongkang ngrumat anak bojo

haram lamun pasrah borong moso bodo

Sak pantese nyambut gawe kena bahe

dagang tani tuprih sekul sak lawuhe

Dadi khatib juru tulis dadi guru

dadi opsir dadi pulisi gak keliru

Jahit ngumbah lan liyane aja nakal

kabeh mahu kanggo sebab rizki halal. ${ }^{15}$

Kalau sudah dewasa wajib bekerja

mencari rizki yang halal, jangan terlalu santai.

Apalagi kalau sudah beranak-istri

haram membiarkan mereka terlunta-lunta.

Bekerjalah yang pantas, apa saja.

\footnotetext{
${ }^{14}$ Musthofa, 4.

${ }^{15}$ Musthofa, 5-6.
} 
berdagang, bertani, mencari sesuap nasi dan lauknya.

Menjadi penceramah, juru tulis, guru

jadi opsir ataupun polisi tak masalah.

Menjadi penjahit atau buruh laundry, asal jangan nakal.

agar semua rizkimu menjadi halal.

Pribadi yang sudah dewasa mendapat beban untuk berkarya dan bekerja. Tentu saja ketika bekal ilmunya sudah cukup. Salah satu tujuannya adalah menghidupi diri sendiri, agar bisa mandiri dan tidak menjadi beban bagi keluarga, lingkungan, dan negaranya. Sebaliknya, seseorang harus memiliki peran dalam pengembangan negaranya. Syiir Mitra Sejati mengajarkan agar dalam menjalani pekerjaan dengan sungguh-sungguh, jangan terlalu santai.

Kewajiban ini akan menjadi lebih berat lagi ketika seseorang dewasa sudah berkeluarga. Ia wajib memberikan nafkah kepada anak dan istrinya. Haram baginya membiarkan mereka kelaparan dan terlunta-lunta. Mitra Sejati memberikan dua prinsip dasar dalam bekerja. Pertama, kerja apa saja jangan malu dan tidak perlu gengsi. Boleh bertani, berdagang, menjadi penceramah, guru, pengadministrasi di kantor, menjadi polisi, opsir, polisi, jaksa, bahkan menjadi buruh pun tak masalah. Kedua, bekerja dengan jujur, tidak nakal agar mendapatkan rizki yang halal. Kehalalan rizki ini akan membawa keberkahan bagi kehidupan.

Syiir Mitra Sejati juga mengajarkan bagaimana menjadi warga negara yang baik dalam konteks sosial kemasyarakatan. Hal ini dimulai dengan menjaga silaturahmi dengan kawan dan kerabat, baik dalam kondisi sehat apalagi jika kerabat dalam kondisi sakit, meninggal dunia, atau menyelenggarakan resepsi. Maka silaturahmi menjadi hal yang sangat dianjurkan, bahwa wajib adanya. Syiir Mitra Sejati mengajarkan bagaimana tata krama dalam ketiga kesempatan yang berbeda nuansa tersebut. ${ }^{16}$

Generasi muda juga harus menjaga tata krama sebagai bangsa Timur yang berbeda watak dengan bangsa Barat.

Iki zaman lanang wadon kudu majeng, sumawena ing bab ngaji kudu mempeng.

Do sekolah iku peci wus zamane, sapa sing keset bakal getun ing mburine.

${ }^{16}$ Musthofa, 7-8. 
Nanging awas aja tiru wong kemajuan, nganti lali hukum syara kanggo guyon.

Rina wengi dha buncengan dha gandengan, lanang wadon dudu mahram liwat ratan. Ora malu podo lali budi Timur, podo katularan Barat kalantur-lantur. Ajar cara Inggris cara londo kena, cara singkek cara apa bahe kena.

Nanging watak watek budi kang utama, ora kena gingsir senajan sak tuma. ${ }^{17}$

Zaman sekarang lelaki perempuan harus maju bersama, demikian halnya, mengaji harus tambah giat.

Sekolah tinggi memang sudah zamannya, siapa yang malas akan menyesal akhirnya. Tapi jangan ikut orang yang terlalu maju, sampai lupa diri, hukum Islam dijadikan permainan.

Siang-malam saling berboncengan, saling bergandengan, antara lelaki perempuan yang bukan mahram di jalanan. Tak punya malu, lupa etika Timur. terpengaruh budaya Barat terlampau larut. Mempelajari budaya Inggris atau budaya bule itu boleh saja, budaya Tiongkok, budaya apa pun juga boleh.

Tetapi menjaga watak dan karakter etika yang baik, tidak boleh surut meski sebiji kutu.

Syiir Mitra Sejati menegaskan bahwa kemajuan adalah fitrah dan keniscayaan bagi sebuah generasi. Sudah menjadi hal yang tak bisa dibantah bahwa satu generasi berbeda dengan generasi sebelumnya. Setiap generasi memiliki jiwa zaman yang berbeda. Hal inilah yang diamati oleh KH. Bisri Musthofa. Ia memperhatikan bahwa generasi di bawahnya, yang lahir sesudah era revolusi kemerdekaan memiliki kecenderungan yang agak bebas untuk tidak tunduk kepada budaya Timur.

Apalagi daerah yang ditinggali KH. Bisri adalah area pesisir yang mudah sekali bersinggungan budaya luar karena faktor ekonomi dan budaya. Hal ini sangat berbeda dengan Jawa di area sentrum seperti Mataraman yang terkesan lebih rigid dan nyari selalu terkait kekuasaan

\footnotetext{
${ }^{17}$ Musthofa, 8 .
} 
politik. ${ }^{18}$ Maka tak mengherankan problem lintas budaya ini menjadi perhatian serius oleh KH. Bisri Musthofa.

KH. Bisri Musthofa melihat hal ini dalam pergaulan pemuda yang cenderung mengesampingkan etika Timur dan tata aturan hukum Islam. Dalam aturan hukum Islam, lelaki perempuan yang bukan mahram haram bercampur (ikhtilath), kecuali keduanya sudah dihalalkan dengan ikatan pernikahan. Demikian halnya, etika Timur mengajarkan adanya unsur malu karena keduanya belum menjadi pasutri yang sah.

$\mathrm{KH}$. Bisri mengecam perilaku pergaulan bebas yang mulai merebak di kalangan masyarakat. Menurutnya, mempelajari budaya asing adalah hal yang lazim dan tidak bisa dicegah karena jiwa zamannya memang menuntut adanya kebebasan. Namun demikian, menjaga karakter dan watak bangsa Timur, juga menjaga etika Timur yang baik tidak bisa dinego dan tidak bisa ditoleransi. Ia tak boleh surut mesji sebiji kutu.

Dalam upaya menjaga budaya dan etika kebangsaan Timur inilah, salah satu yang mendapat perhatian adalah peran penting orangtua. Syiir Mitra Sejati dalam bab terakhir memberikan penjelasan panjang terkait hal ini.

Ibu Bapak wajib mulang ing putrane, lanang wadon nganti ngerti agamane.

Lamun ora, kongang wajib masrahake, marang wongkang pinter kaya mondokake.

Ngilmu umum uga perayuga ngertine, nanging ojo lali ngilmu agamane.

Sebab ibu bapak bakal pada mati, lamun ngalim putra mesti pada gati.

Dungaake tahlilake bengi rina, dadi ibu bapak mengko ora tuna.

Dawuh hadits arikala anak adam, wus kapundut najan isih ana ranjam. Kabeh ngamal ganjaran banjur pedot, liya telu kang tsawabe tansah modot. Ping sijine amal jariyah pindone, ngilmu nafik anak soleh ping telune. ${ }^{19}$

${ }^{18}$ Aziz, "Produksi Wacana Syiar Islam dalam Kitab Pegon Kiai Saleh Darat Semarang dan Kiai Bisri Musthofa Rembang," 113.

${ }^{19}$ Musthofa, Syiir Mitra Sejati Nerangake Ing Bab Budi Pekerti, 9. 
Ibu Bapak wajib mendidik anaknya,

laki perempuan agar paham agama.

Jika tidak mampu, maka wajib memasrahkan,

kepada orang yang paham agama, seperti di pesantren.

Harus menguasai ilmu umum,

tetapi jangan sampai ilmu agama terlewat.

Sebab Ibu Bapak kelak akan wafat,

jika paham agama, anak akan tetap perhatian.

Mendoakan membacakan tahlil siang malam,

sehingga Ibu Bapak tidak bakal merugi.

Hadits Rasul menyatakan, ketika seorang anak Adam, wafat meskipun ia masih di atas ranjang.

Semua amal akan terputus, kecuali tiga hal yang pahalanya masih terus mengalir.

Yang pertama amal jariyah, kedua

ilmu yang bermanfaat, lalu ketiga anak saleh yang mendoakan.

Syiir Mitra Sejati menempatkan orangtua sebagai aktor penting. Selain untuk menjaga tradisi, hal ini juga penting untuk menjaga agama dan menjaga kepentingan orangtua kelak ketika mereka sudah tiada. Strategi agama dan strategi tasawuf digunakan KH. Bisri untuk menyampaikan pesannya. Stategi agama mewujud dalam upayanya membujuk orangtua untuk mendidik agama putra-putri mereka. Sekaligus memondokkan putra ketika mereka tak mampu mendidiknya.

Sedangkan strategi tasawuf digunakan dengan memilih hadits yang bersifat eskatologis. Yakni terkait dengan kematian dan nasib mereka di alam akhirat. Tentu saja dengan begini, para orang tua akan lebih perhatian terhadap transmisi budaya Timur kepada anak turun mereka.

\section{H. Simpulan}

Dalam dua karyanya, KH. Bisri Musthofa memiliki perhatian penuh terhadap generasi penerus bangsa. Ia ingin agar generasi penerus memiliki rasa cinta tanah air yang menyala. Ia juga menekankan agar generasi penerus memiliki karakter yang kuat dan kokoh. Hal ini dilandasi dengan ilmu pengetahuan yang cukup, wawasan yang luas, karakter ketimuran yang kental, bervisi relijius, dan memiliki kedewasaan mental yang matang.

Dengan demikian, diharapkan generasi penerus bangsa siap bertanggung jawab untuk mengemban amanah dalam bidang-bidang 
strategis dalam lingkungan keluarga, pendidikan, sosial, ekonomi, hukum, hingga politik. Peran-peran ini perlu diisi oleh generasi yang baik, karena di pundak merekalah masa depan bangsa ini dipertaruhkan. Semua hal penting ini ditekankan dalam Kitab Syiir Ngudi Susilo secara garis besar dan dalam Syiir Mitra Sejati secara detil dan mendalam[.]

\section{REFERENSI}

Anderson, Benedict. Imagined communities: Reflections on the origin and spread of nationalism. Verso Books, 2006.

Aziz, Munawir. "Produksi Wacana Syiar Islam dalam Kitab Pegon Kiai Saleh Darat Semarang dan Kiai Bisri Musthofa Rembang." Jurnal Afkaruna 9, no. 2 (Desember 2013): 112-28.

Fatkhullah, Faiz Karim. "Pengalaman Spiritual K.H. Bisri Mustofa dalam Naskah Manasik Haji: Tinjauan Sosiologi Sastra (the Spiritual Experience of Kh Bisri Mustofa in Manasik Haji Manuscript: a Literary Socio- Logical Review)." Metasastra 6, no. 2 (2013): 65-82.

Khalim, Samidi. "Akhlak Santri antara Teks dan Konteks." Analisa Journal of Social Science and Religion 16, no. 1 (2009): 36-49.

Musthofa, Bisri. Syiir Mitra Sejati Nerangake Ing Bab Budi Pekerti. Surabaya: Muhammad bin Ahmad Nabhan, n.d.

Ricklefs, Merle Calvin. Sejarah Indonesia Modern, 1200-2004. Jakarta: Penerbit Serambi, 2005.

Rohkmad, Abu. "Telaah Karakteristik Tafsir Arab-Pegon Al-Ibriz." Analisa Journal of Social Science and Religion 18, no. 1 (3 Juni 2011): 27-38.

Septiningsih, Lustantini. “Tema Nasionalisme Dalam Pembelajaran Sastra: Upaya Menumbuhkan Semangat Kebangsaan*" Kajian Sastra 34, no. 2 (2010). 